\title{
Relação entre folga financeira e desempenho econômico em empresas cinquentenárias e não cinquentenárias
}

\author{
Relación entre holgura financiera y desempeño económico en empresas cincuentenarias y no cincuentenarias \\ Relation between Financial Slack and Economic Performance in Companies above and below 50 Years Old
}

Tarcísio Pedro da Silva

Universidade Regional de Blumenau, Brasil

tarcisio@furb.br

ORCID: http://orcid.org/0000-0002-2370-791X

Leonardo Bernardi Rohenkohl

Universidade Regional do Noroeste do Estado do Rio

Grande do Sul, Brasil

ORCID: http://orcid.org/0000-0002-7397-9157

DOI: https://doi.org/10.11144/Javeriana.cc19-47.ffde Redalyc: http://www.redalyc.org/articulo.oa? $\mathrm{id}=151556994007$

\section{Luana Sara Bizatto}

Centro de Educação de Jovens e Adultos, Brasil

ORCID: http://orcid.org/0000-0002-2259-989X

\section{Resumo:}

O objetivo deste estudo é analisar a relação entre a folga financeira e o desempenho econômico em empresas cinquentenárias e não cinquentenárias. $\mathrm{O}$ intuito é fomentar pesquisas que levem em consideração as diferenças entre empresas com distinto tempo de permanência no mercado, devido a que existe escassez de pesquisas que considerem a idade da empresa. Para a realização do estudo, foram consultadas empresas listadas nos indicadores Índice Brasil 100 (IBrx-100) e Índice de Governança Corporativa - Novo Mercado (IGC-NM), da Bolsa de Valores, Mercadorias e Futuros de São Paulo, com uma amostra de 78 empresas não cinquentenárias e 34 empresas cinquentenárias. Por meio da estatística descritiva e da correlação canônica, concluiu-se que tanto em empresas cinquentenárias como em não cinquentenárias a folga financeira tem relação com o desempenho econômico. Assim, as empresas cinquentenárias possuem grau de relação mais forte entre os dois conjuntos de indicadores que as não cinquentenárias. Desta forma, é possível que as empresas devam considerar seu tempo de mercado, ou seja, o grau de estabilidade e maturidade que possuem, para compreenderem o menor ou maior uso da folga financeira com intuito de elevarem seus desempenhos econômicos, uma vez que uma maior relação entre a folga financeira e o desempenho econômico é perceptível em empresas com mais de 50 anos. Palavras-chave: folga financeira, desempenho econômico, empresas cinquentenárias, empresas não cinquentenárias.

\section{Resumen:}

El objetivo de este estudio es analizar la relación entre la holgura financiera e el desempeño económico en empresas cincuentenarias y no cincuentenarias. El propósito es fomentar las investigaciones que tengan en consideración las diferencias entre empresas con distinto tiempo de permanencia en el mercado, debido a que existe escasez de investigaciones que consideren la antigüedad de la empresa. Para la realización del estudio fueron consultadas empresas enlistadas en los indicadores Índice Brasil 100 (IBrx-100) e Índice de Gobernanza Corporativa - Nuevo Mercado (IGC-NM), de la Bolsa de Valores, Mercancías y Futuros de São Paulo, con una muestra de 78 empresas no cincuentenarias y 34 empresas cincuentenarias. Por medio de la estadística descriptiva y de la correlación canónica, se concluyó que tanto en empresas cincuentenarias como no cincuentenarias la holgura financiera tiene relación con el desempeño económico. Así, las empresas cincuentenarias poseen un grado de relación más fuerte entre los dos conjuntos de indicadores que las no cincuentenarias. De esta forma, es posible que las empresas deban considerar su tiempo en el mercado, es decir, el grado de estabilidad y madurez que poseen, para comprender el menor o mayor uso de la holgura financiera con el propósito de elevar sus desempeños económicos, una vez que una mayor relación entre la holgura financiera y el desempeño económico es perceptible en empresas con más de 50 años.

Palabras clave: holgura financiera, desempeño económico, empresas cincuentenarias, empresas no cincuentenarias.

\section{Abstract:}

This study aims to analyze the relationship between financial slack and economic performance in the companies above and below fifty years old. This is intended to promote researches taking into account the differences between companies with different 
seniority in the market, since there is a lack of research dealing with the seniority of the companies. To conduct this study, companies listed in the index Brazil 100 (IBrx-100) and the Corporate Direction Index-New Market (IGC-NM) from the Future, Goods and Stock Exchange of São Paulo were consulted. It provided a sample of 78 companies below fifty years old and 34 companies above fifty years old. By using the descriptive statistics and the canonical-correlation analysis, it is concluded that in both companies, above and below fifty years old, the financial slack is related to the economic performance. In addition, the companies above fifty years old show a relationship between these two sets of indicators stronger than the companies below fifty years old. This way, the companies may be willing to consider their seniority in the market, i.e., their level of stability and maturity in order to understand the higher or lower use of the financial slack to enhance their economic performance. The fact is that a greater relationship between financial slack and economic performance is perceived in the companies above fifty years old.

Keywords: financial slack, economic performance, companies above 50 years old, companies below 50 years old.

\section{Introdução}

As empresas que conseguem absorver as mudanças do ambiente em que estão inseridas alcançam efetividade na sua continuidade, o que mostra uma boa saúde organizacional, provida pelo correto gerenciamento da contabilidade financeira (Vanacker, Collewart \& Paeleman, 2013). Desta forma, a folga financeira, que neste estudo será sinônimo de liquidez, e o desempenho econômico (ou rentabilidade empresarial), são fatores a serem analisados pelas empresas, principalmente quando houver impacto mútuo (Daniel, Lohrke, Fornaciari \& Turner, 2004). Com esse intuito, a análise desses indicadores econômico-financeiros, permite antever o desempenho com previsibilidade assertiva e serve de grande valia para a gestão da empresa (Ferreira, 2005; Ross, Westerfield \& Jaffe, 2015).

A folga financeira é representada pelos ativos líquidos que não estão aplicados a nenhuma atividade organizacional, o que a faz necessária para eventuais acontecimentos na empresa e de grande valia às finanças da organização (Dai \& Kittilaksanawong, 2014). Esta análise faz-se importante principalmente para situações mais delicadas, como em casos de recessão, crise, expansão ou desenvolvimento de novos produtos, onde são necessários maiores ou menores níveis de recursos próprios (Namiki, 2012).

O desempenho econômico está totalmente relacionado com a rentabilidade da empresa (Matarazzo, 2010). Contudo, a análise desse fator pode ser considerada complicada e abrangente, devido a fatores como a liquidez e o tempo da empresa no mercado, que podem impactar de diferentes e imprevisíveis formas e, consequentemente, com diversas metodologias para sua mensuração.

A relação entre a folga organizacional e a rentabilidade é estudada por diferentes autores (Bourgeois, 1981; Wiseman \& Borimiley, 1996; Cheng \& Kesner, 1997; Nohria \& Gulati, 1997; Daniel et al. 2004; Bradley; Shepherd \& Wiklund, 2011; Vanacker et al. 2013; Laffranchini \& Braun, 2014). Entre as correlaçóes verificadas, especificamente entre folga financeira e rentabilidade, a literatura aponta à utilização de não só um tipo de folga, mas também para o uso de outros múltiplos tipos (Daniel et al. 2004).

O tempo da empresa no mercado, como um determinante importante tanto na folga financeira como no desempenho econômico, faz com que as empresas possam ser diferenciadas. As empresas mais antigas possivelmente possuem mais maturidade, conseguem prever melhor as necessidades dos recursos e, consequentemente, fazem um uso mais eficiente da folga em comparação com empresas mais jovens, devido a que já tiveram experiência com diferentes tipos de recursos, pois souberam administrar de forma a elevar o seu desempenho (George, 2005). Para Bradley et al. (2011), as empresas mais novas têm maiores dificuldades para obterem recursos de capital, independente do setor de atividades em que estas empresas atuam. Assim, acredita-se que essas podem depender mais da folga financeira para alcançarem a rentabilidade desejada (Vanacker et al. 2013).

A partir do exposto, este estudo tem a seguinte pergunta para ser respondida: Qual é a relação entre a folga financeira e o desempenho econômico em empresas cinquentenárias e não cinquentenárias? Como 
objetivo, esta pesquisa visa analisar a relação entre a folga financeira e o desempenho econômico em empresas cinquentenárias e não cinquentenárias.

As motivações para a realização desta pesquisa são evidenciadas em estudos que sugerem que o comportamento entre as variáveis de folga financeira e desempenho econômico pode não ser linear, mas sim curvilíneo, e com um relacionamento positivo (Tan \& Peng, 2003; Ju \& Zhao, 2009). Anteriormente, nos achados de Wiseman e Bromiley (1996), evidencia-se que a folga disponível, considerada como liquidez corrente, possui uma relação positiva com as variáveis de desempenho econômico e, ainda mais, que a perda de recursos próprios (folga financeira) aumenta os riscos organizacionais, os quais podem impactar diretamente no desempenho organizacional. Desta forma, uma lacuna de pesquisa encontrada na literatura é a comparação desses resultados entre empresas cinquentenárias e não cinquentenárias, pois para George (2005), os níveis de caixa e de disponibilidades financeiras nas organizações podem modificar-se de acordo com o tempo da empresa no mercado. Desta maneira, precisa-se de pesquisar temáticas financeiras que considerem os diferentes níveis de idade de empresas.

Para John, Li e Pang (2016) a quantidade de folga financeira em uma empresa pode demonstrar com clareza as características da diretoria, traços e níveis de governança corporativa, sua gestão de riscos e a capacidade de investimento em pesquisa para desenvolvimento. Desta forma, esta pesquisa busca apresentar evidências estatísticas acerca da correlação entre a folga financeira e o desempenho econômico, ao utilizar o tempo da empresa no mercado como diversos agrupamentos amostrais para assim inferir acerca das diferenças entre os variados cenários de idade empresarial. O que contribui com os estudos acerca da disponibilidade financeira e seus impactos e a relação com características empresariais. Acredita-se que estudos como o presente podem ser úteis tanto para o mercado financeiro quanto para as empresas, visto que para autores que contribuíram com o tema, o gerenciamento da folga financeira é imprescindível para a continuidade empresarial (Satta, Parola, Penco \& Esposito de Falco, 2016; Shaikh, O’Brian \& Peters, 2018).

\section{Referencial Teórico}

A capacidade que as empresas têm de se adaptarem às mudanças do ambiente em que elas estão inseridas é conhecida como folga organizacional, o que é um importante fator no estudo das organizações (Bourgeois, 1981; Nohria \& Gulati, 1996; Greenley \& Oktemgil, 1998). Este conceito apareceu várias vezes na literatura com o intuito de explicar os tipos de comportamentos organizacionais (Bourgeois, 1981).

Para Antle e Eppen (1985), a folga organizacional caracteriza-se pelo excesso de recursos destinados além do mínimo necessário para a concretização das tarefas atribuídas. Segundo Damanpour (1987), ela é a diferença entre os recursos que a organização possui e o que é minimamente empregado para manter suas obrigações. O estudo de Sharfman, Wolf, Chase e Tansik (1988) tem o mesmo conceito para folga organizacional que Bourgeois (1981), porém com duas adições. Em primeiro lugar, os recursos são considerados como folga se estes estiverem visíveis aos gestores para um futuro uso. Em segundo, é importante que a folga seja variável para proteger a firma de várias formas, pois diferentes tipos de folgas dão aos gestores uma maior ou menor flexibilidade para lidar com questóes internas e externas que afetarão à empresa.

A partir do conceito de folga organizacional, dois conceitos de finanças corporativas são usuais: liquidez e folga financeira. A liquidez é a propriedade do ativo de ser transformado em recursos monetários, enquanto que a folga financeira, que envolve a liquidez, é a competência da empresa de conseguir novos recursos junto ao mercado, seja por meio de linhas previamente contratadas ou não (Campos \& Nakamura, 2015). O termo folga financeira foi proposto primeiramente por Myers e Majluf (1984) como um recurso que permite à empresa evitar financiamentos externos e separar decisóes de investimento dos conflitos de interesses entre os stockholders e os investidores novos. 
A folga financeira fornece às empresas a autonomia e recursos necessários para explorar novas oportunidades no mercado em que está inserida (Kim, Kim \& Lee, 2008). Esta é uma espécie de proteção que a empresa tem ao disponibilizar novos recursos para a sua continuidade, já que o financeiro não é estático e pode apresentar resultados negativos (Laffranchini \& Braun, 2014; Dai \& Kittilaksanawong, 2014).

Uma empresa com altos níveis de folga financeira pode ter um processo de inovação mais acelerado e um aumento no desempenho (Satta et al., 2016, Shaikh et al., 2018). Apesar desses argumentos, conforme Laffranchini e Braun (2014) o excesso de folga financeira faz com que as empresas tendam a não explorar novas oportunidades ou mesmo aplicar ações estratégicas inadequadas. Isto, leva-lhes muito tempo para identificar seus erros estratégicos e resulta numa diminuição no desempenho.

Em contrapartida, a escassez de folga financeira também gera consequências negativas pois reduz as escolhas de decisão sobre determinadas situações já que há escassez de recursos disponíveis para tais (Nohria \& Gulati, 1996; Singh, 1986; Namiki, 2012). Portanto, para os autores, pouca ou muita folga pode ter implicações negativas no desempenho da empresa, devido a que a afirmação quanto a uma quantidade de folga financeira ideal para cada empresa é um montante complexo de calcular, visto que esse valor se modificará conforme a gestão da empresa, a estrutura e a realidade em que ela se encontra e desta forma alterará os resultados em positivos ou negativos (Nohria \& Gulati, 1996; Singh, 1986; Namiki, 2012; Laffanchini \& Braun, 2014).

Para o cálculo da folga financeira usa-se o ativo circulante como base, pois assim consegue-se abranger apenas os valores com altos índices de liquidez das companhias (Weston \& Brigham, 2000, Iyer \& Miller, 2008). Ainda, o capital de giro pode ser considerado um forte indicador para a análise pois, segundo Appuhami (2008), este pode impactar na rentabilidade da empresa pois considera-se como uma importante variável de liquidez e que, por consequência, proporciona segurança à empresa quando gerenciado (Eljelly, 2004).

A gestão do capital de giro é a essência de um gerenciamento eficiente, pois apresenta uma grande relevância na continuidade da empresa, ao mesmo tempo que a sua otimização pode se tornar importante na rentabilidade da empresa no futuro (Quayyum, 2011; Desai \& Oza, 2015). Em um estudo comparativo entre a liquidez e a rentabilidade de Desai e Oza (2015), foi assumido que o capital de giro possui um papel semelhante à liquidez corrente quando ambas influenciam na solvência a curto prazo da empresa.

As palavras "econômico" e "financeiro" são constantemente usadas em estudos de finanças empresariais, por isso é importante entender a diferença que há entre elas, principalmente as junções entre desempenho econômico e desempenho financeiro. O primeiro, o econômico, refere-se à rentabilidade; o segundo, o financeiro, está relacionado com o dinheiro e as variações de caixa (Matarazzo, 2010).

Os indicadores de rentabilidade (desempenho econômico) visam dar suporte a análise de determinados parâmetros que melhor revelam as dimensões da empresa (Assaf Neto, 2010). "As medidas de rentabilidade permitem aos analistas avaliar os lucros da empresa em relação a um dado nível de vendas, nível de ativos ou o investimento dos proprietários" (Gitman, 2010, p. 58). A partir disto, vários indicadores podem ser apontados como referência para a rentabilidade; as mais usadas pela literatura são a rentabilidade sobre o ativo (ROA) e a rentabilidade sobre o capital próprio (ROE). Nesta pesquisa, também serão levadas em consideração as variáveis margem líquida $(\mathrm{ML})$ e margem bruta $(\mathrm{MB})$.

A folga disponível (liquidez corrente), no estudo de Wiseman e Bromiley (1996), possui uma relação positiva com a ROA e a ROE -indicadores de desempenho econômico-. Em sua meta-análise, Daniel et al. (2004) observaram que todos os três estudos que fizeram relação entre folga financeira e desempenho econômico tiveram resultados similares, pois apresentaram relacionamento positivo, ou seja, as empresas utilizam a folga para melhorar seus desempenhos. Ainda, em seus resultados, mostram que a busca das empresas não consiste em níveis elevados de folga, mas sim em níveis adequados, afim de elevar seus desempenhos. 
No estudo de Eljelly (2004), o indicador de liquidez corrente, bem como cash gap, foi utilizado para a mensuração da liquidez. Para o cálculo da rentabilidade foi utilizado o lucro operacional em relação ao ativo operacional e, constatado em seus resultados, foi uma relação estatística negativa entre os indicadores de liquidez corrente e rentabilidade. Quanto ao cálculo de rentabilidade, Braga, Nossa e Marques (2004) usaram o ROA e o ROE; como contribuições da pesquisa, os autores destacaram que as avaliações econômicofinanceiras fornecem uma ampla visão sobre os diferentes setores de atividades da empresa.

Quanto à relação dos indicadores de liquidez e rentabilidade, pode ser destacada a pesquisa de Pimentel e Lima (2011), na qual os autores utilizaram a liquidez seca como variável de liquidez. Já para os indicadores de rentabilidade, consideraram o resultado trimestral antes dos impostos e despesas financeiras dividido pelo ativo total. Como conclusões, encontraram relações temporais positivas tanto para as empresas quanto para os dados, o que convergiu variáveis, ou seja, baixos indicadores de liquidez estão relacionados com baixos indicadores de rentabilidade.

Namiki (2012) investigou a relação entre a redução da folga e o desempenho em empresas japonesas, as quais diminuíram substancialmente o desempenho de lucro devido à Grande Recessão que aconteceu no Japão em 2008 Notou-se em seu estudo que os gestores que tomaram as decisões mais "agressivas" obtiveram o melhor desempenho de crescimento em vendas. As decisóes consistiram em aumentar os custos e despesas de marketing, como também na redução das folgas financeiras, além da realização das vendas dos ativos. Dessa forma, as empresas que possuíam maiores níveis de folga fizeram uma redução devido a que a recessão alcançou melhor desempenho de lucro, o que evidencia que nem sempre excesso de folga financeira corresponde a benefícios econômicos futuros.

Conhecida a relação positiva entre os níveis de liquidez e desempenho econômico dos estudos anteriores supracitados, há fatores, como a idade empresarial, que podem alterar essa correspondência (Bradley et al., 2011). Desta forma, para entender a influência da folga financeira no desempenho econômico da empresa, deve-se considerar como essa é alocada e o quão é necessária conforme à realidade empresarial que está sendo analisada (Bradley et al., 2011).

Os níveis de recursos organizacionais e a folga muitas vezes são afetados pela idade da empresa (Voss, Sirdeshmukh \& Voss, 2008). Conforme George (2005) e os autores Hitt, Xu e Carnes (2016), as empresas mais antigas possuem maior maturidade e melhor experiência em administrar recursos do que as mais jovens, pois a estabilidade é um fator mais presente. Esses ambientes, considerados estáveis, caracterizam-se por optarem com menos frequência a fontes de recursos externos, apesar de apresentarem menores incertezas aparentemente de investimentos, pois tanto os investidores como o mercado têm a percepção de que empresas, com esses ambientes, possuem potenciais mais limitados de crescimento (Gompers \& Lerner, 2001).

Por este motivo, em vez de investimentos é a presença de folga financeira a que pode elevar mais a rentabilidade em ambientes estáveis e que possibilita, especialmente a essas empresas, experimentar novos produtos, serviços, processos e ideias (Woodman, Sawyer \& Griffin, 1993). Assim, este estudo tem como hipótese que as empresas cinquentenárias apresentam uma relação significativa e positiva entre a folga financeira e o desempenho econômico.

Conforme os resultados de Bradley et al (2011), a folga financeira tem menor influência em empresas que apresentam ambientes mais dinâmicos; característica evidenciada, em maior proporção, nas empresas com menos tempo no mercado. Segundo os autores, a folga financeira para essas empresas torna-se mais importante para melhorar o desempenho apenas em situações consideradas mais críticas. Assim, essas empresas geralmente são mais voltadas aos seus conhecimentos ou habilidades, o que as faz depender mais do estabelecimento de competências e capacidades para o alcance de uma posição no mercado, já que também possuem uma estrutura organizacional pequena, o que, consequentemente, dificulta também seus relacionamentos com outras empresas (Damanpour \& Wischnevsky, 2006; Bradley et al., 2011).

Além disso, uma possível justificativa acerca da menor influência da folga financeira no desempenho econômico em empresas com menos idade, conforme aos autores Acemoglu, Aghion, Lelarge, Van Reenen e 
Zilibotti (2007) e Avadikyan, Lhuillery e Negassi (2016), pode ser devido às empresas jovens terem menos experiência com tecnologias e arranjos organizacionais. Desta forma, outra hipótese do estudo é que a relação positiva entre folga financeira e desempenho econômico das empresas não cinquentenárias será menor comparada às cinquentenárias.

\section{Metodologia}

A presente pesquisa caracteriza-se como descritiva, documental e quantitativa, com uma amostra constituída por empresas de capital fechado, as quais estão listadas na Bolsa de Valores, Mercadorias e Futuros de São Paulo (BM\&FBovespa). Isto, devido a que o Brasil é uma das maiores economias da América do Sul e é um dos mercados acionários mais dinâmicos da América Latina. Contudo, seu papel no mercado financeiro mundial ainda é baixo quando comparado com outras economias emergentes, o que incita e motiva à realização de mais pesquisas (Dalmácio, 2009).

Inicialmente, consultou-se o site da BM\&FBovespa com o fim de coletar os dados sobre as empresas e assim captar o vinculo de empresas que estão relacionadas nos agrupamentos Índice Brasil 100 (IBrx-100) e Índice de Governança Corporativa - Novo Mercado (IGC-NM). Esses indicadores foram escolhidos pois, segundo o site da BM\&FBovespa, as empresas do IBrx-100 são consideradas as cem companhias com os maiores índices de negociabilidade e porque as pertencentes ao IGC-NM são referentes da governança corporativa. Além disso, conforme Silveira (2002), as empresas listadas no IGC-NM estão mais voltadas a uma maior transparência na divulgação de informações abrangentes, o que derivou na completa informação contábil disponibilizada nos meios pesquisados. Assim, a população total de entidades resultou em 154 empresas, das quais foram excluídas as holdings, instituições financeiras, empresas com menos de 5 anos e as com mais de 100 anos, o que totalizou em 119 companhias. As empresas com menos de 5 anos foram excluídas para que a falta de informações financeiras dessas empresas não afetasse o resultado da correlação canônica nem o dos demais testes aplicados a amostra. As empresas com mais de 100 anos foram excluídas da amostra para que não houvessem confusões conceituais acerca de empresas cinquentenárias e centenárias, pois a pesquisa somente considera empresas cinquentenárias.

O banco de dados Economática foi usado para a coletar os dados financeiros de 2011 até 2015, que serviram de base para o cálculo de indicadores. A partir dessas informações, mais 7 empresas foram excluídas por não apresentarem todos os valores pesquisados. Com isso, a amostra total da pesquisa resultou em 112 empresas, onde 34 são empresas cinquentenárias (de 51 até 99 anos) e 78 não cinquentenárias (de 5 até 48 anos). Destas também foram excluídas aquelas que estavam no limite da classificação ( 49 e 50 anos).

A relação de indicadores e as suas respectivas equações estão evidenciadas na Tabela 1. Nos estudos anteriores, o indicador ROA é utilizado para o cálculo da rentabilidade (Laffranchini \& Braun, 2014; Su, Xie \& Li, 2009); para este, quanto maior o seu valor, melhor para a empresa. Este também indica o retorno dos investimentos totais os quais são representados por seus ativos totais (Camargos \& Barbosa, 2005).

$\mathrm{O}$ indicador ROE evidencia o retorno do capital gerado na empresa que foi investido por parte dos acionistas, por isso que quanto maior o seu valor, melhor é o cenário econômico da empresa, como verificado com o ROA. Essas variáveis já foram utilizadas como medida de rentabilidade em estudos anteriores, como Wiseman e Borimiley (1996) e Camargos e Barbosa (2005).

A MB avalia quanto da receita operacional é convertida em lucro bruto. Desta são deduzidos apenas os custos operacionais, com sua determinação antes da dedução de quaisquer outras despesas com juros (Ehrhardt \& Brigham, 2012). Assim, é uma forma de controlar a estrutura de custos da empresa. A última variável de rentabilidade, a ML, indica qual é a capacidade da empresa de converter receita líquida em lucro líquido, pois possibilita verificar se a empresa alcançou eficiência operacional, administrativa e financeira, ou seja, quanto maior o indicador, maior é o desempenho e a eficiência empresarial (Camargos \& Barbosa, 2005). 
As variáveis independentes tratam da folga financeira, das quais utilizam-se três valores de ativo circulante, os quais estão relacionados com a alta liquidez. Os indicadores são: caixa, clientes e capital de giro. Esses indicadores foram divididos pelo total do ativo para que a evidenciação da representatividade dessas contas no ativo total possa ser a maneira de representar os ativos com maior liquidez como folga financeira.

TABELA 1.

Indicadores de folga financeira e desempenho econômico utilizados

\begin{tabular}{|c|c|c|}
\hline \multicolumn{3}{|c|}{ Indicadores de folga financeira e desempenho econômico utilizados } \\
\hline $\begin{array}{l}\text { Variáveis } \\
\text { dependentes }\end{array}$ & Equações & Pesquisas \\
\hline ROA & $\frac{\text { Lucro líquido }}{\text { Ativo total }}$ & $\begin{array}{l}\text { (Wiseman \& Borimiley, 1996; Scarpel \& } \\
\text { Milioni, 2001; Braga et al., 2004; Camargos } \\
\text { \& Barbosa, 2005; Lin \& Zhang, 2009; } \\
\text { Mathur \& Banchuenvijit, 2007; Quayyum, } \\
\text { 2011) }\end{array}$ \\
\hline ROE & $\frac{\text { Lucro líquido }}{\text { Patrimonio líquido }}$ & $\begin{array}{l}\text { (Wiseman \& Borimiley, 1996; Braga et al., } \\
\text { 2004; Lin \& Zhang, 2009; Mathur \& } \\
\text { Banchuenvijit, 2007) }\end{array}$ \\
\hline MB & $\frac{\text { Lucro bruto }}{\text { Receita líquida }}$ & (Camargos \& Barbosa, 2005). \\
\hline ML & $\begin{array}{l}\text { Lucro líquido } \\
\text { Receita líquida }\end{array}$ & (Camargos \& Barbosa, 2005) \\
\hline $\begin{array}{l}\text { Variáveis } \\
\text { independentes }\end{array}$ & Equações & Pesquisas \\
\hline Caixa & Caixa & (Yu, Miche, Severin \& Lendasse, 2014) \\
\hline Clientes & $\frac{\text { Clientes }}{\text { Ativo total }}$ & (Mylonidis \& Kelnikola, 2005) \\
\hline $\begin{array}{l}\text { Capital de } \\
\text { giro }\end{array}$ & $\begin{array}{l}\text { Ativo circulante } \\
\text { - Passivo circulante }\end{array}$ & (Desai \& Oza, 2015) \\
\hline
\end{tabular}

Fonte: elaborada pelos autores

Com base no objetivo da pesquisa, optou-se primeiramente por uma análise estatística descritiva, na qual fosse possível evidenciar as diferenças entre a média e os desvios padrões dos indicadores em empresas cinquentenárias e não cinquentenárias. Após, para a análise da correlação entre os dois conjuntos de variáveis, foi proposto o uso da análise de correlação canônica. O resultado desta correlação consiste em combinações lineares dos grupos, aqui uma obtém a maior correlação e assim é determinada como a principal combinação 
linear (Fávero, 2005). Utilizou-se o software Statgraphics para verificar se as combinações lineares formadas pela correlação canônica são significativas.

A correlação canônica é uma técnica estatística que avalia e quantifica a força da relação linear entre variáveis independentes múltiplas e dependentes múltiplas. Deste modo, utiliza-se esta técnica para verificar se há interrelações entre os dois conjuntos, folga financeira e desempenho econômico, e para medir o grau de associação (Fávero, 2005).

Após serem formadas as combinações lineares, as variáveis são denominadas canônicas e o grau de associação existente entre os dois conjuntos de variáveis é medido pela correlação (Mingoti, 2005). Segundo Epley (2001), o modelo (combinação linear) de correlação canônica é:

$$
\left(c_{1} \ldots c_{n}\right)=f\left(p_{1} \ldots p_{n}\right)
$$

Onde são as variáveis dependentes e são as variáveis independentes. Assim, tem-se o par de variáveis canônicas:

$$
U_{1}=a_{1} x_{1}+a_{2} x_{2}+a_{3} x_{3}+a_{4} x_{4} e V_{1}=b_{1} y_{1}+b_{2} y_{2}+b_{3} y_{3}
$$

Onde $a=\left[a_{1}, a_{2}, a_{3}, a_{4}\right]$ e $b=\left[b_{1}, b_{2}, b_{3}\right]$ são variáveis constantes e a correlação entre as variáveis U1 e V1 seja máximizada

Segundo Hair, Anderson, Tatham \& Black (2005), o número de variáveis do menor conjunto de dados, que podem ser tanto dependentes como independentes, correspondem ao número máximo de combinações lineares que podem ser extraídos. Neste estudo, o menor conjunto nos dois grupos (empresas cinquentenárias e não cinquentenárias) é composto de 3 variáveis independentes; logo obtém-se 3 combinações lineares através do pacote estatístico Statgraphics.

Uma das condições para a aceitação do modelo gerado pela correlação canônica é que cada variável apresente pelo menos 10 observações (Fávero, 2005). O presente estudo possui três variáveis dependentes e quatro variáveis independentes, com 175 dados de sub-amostra para as empresas cinquentenárias e 390 dados de sub-amostra para as não cinquentenárias, portanto atende à quantidade mínima de observações.

A força de associação entre os indicadores quantitativos na relação linear pode ser classificada conforme à intensidade de sua correlação. A classificação proposta por Hair et al. (2005), segundo as variações dos coeficientes em relação a força de associação, está exposta na Tabela 2.

TABELA 2.

Regras práticas sobre o valor do coeficiente de correlação (peso canônico) Regras práticas sobre o valor do coeficiente de correlação (peso canônico)

\begin{tabular}{c|c}
\hline $\begin{array}{c}\text { Variação do coeficiente (peso } \\
\text { canônico) }\end{array}$ & Força de associação \\
\hline $\pm 0,91- \pm 1,00$ & Muito forte \\
\hline $\pm 0,71- \pm 0,90$ & Alta \\
\hline $\pm 0,41- \pm 0,70$ & Moderada \\
\hline $\pm 0,21- \pm 0,40$ & Pequena, mas definida \\
\hline $\pm 0,01- \pm 0,20$ & Leve, quase imperceptível \\
\hline
\end{tabular}

Fonte: Hair et al., 2005.

A classificação proposta por Hair et al., (2005) é flexível, pois depende do objetivo da pesquisa e da análise que é feita. No próximo tópico são descritos tanto a análise descritiva quanto o desenvolvimento da correlação canônica. 


\section{Análise de resultados}

Os resultados dos métodos são apresentados e discutidos sob diferentes análises para empresas cinquentenárias e para as não cinquentenárias. Por meio de comparabilidades, destacam-se as possíveis diferenças entre os grupos, ao verificar se a folga financeira é estatisticamente significante para o desempenho econômico.

A partir da compilação e a análise dos dados, é possível delimitar as características das informações entre empresas cinquentenárias e não cinquentenárias, ao ter como base a média e o desvio padrão dos dados coletados. A análise de estatística descritiva é realizada por ano e por indicadores em empresas cinquentenárias e não cinquentenárias, desde 2011 até 2015.

TABELA 3.

Estatistica descritiva das variáveis independentes e dependentes das empresas cinquentenárias e não cinquentenárias

\begin{tabular}{|c|c|c|c|c|c|c|c|c|c|c|c|c|c|c|}
\hline \multirow{9}{*}{ 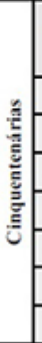 } & \multirow{2}{*}{ Variáveis } & \multicolumn{2}{|c|}{2011} & \multicolumn{2}{|c|}{2012} & \multicolumn{2}{|c|}{2013} & \multicolumn{2}{|c|}{2014} & \multicolumn{2}{|c|}{2015} & \multicolumn{3}{|c|}{ Total } \\
\hline & & Med. & DP & Med. & DP & Med. & DP & Med. & DP & \multirow{2}{*}{$\frac{\text { Med. }}{9,78}$} & \multirow{2}{*}{$\begin{array}{c}\text { DP } \\
7,93\end{array}$} & \multirow{2}{*}{$\begin{array}{l}\text { Méd. } \\
8,632\end{array}$} & \multirow{2}{*}{$\begin{array}{c}\text { DP } \\
7,62\end{array}$} & \multirow{2}{*}{$\begin{array}{r}\text { Coef. var. } \\
0,89\end{array}$} \\
\hline & Caixa & 7,59 & 7,91 & 7,66 & 6,81 & 8,82 & 7,89 & 9,31 & 7,6 & & & & & \\
\hline & Clientes & 13,78 & 10,84 & 14,14 & 10,84 & 12,9 & 9,18 & 12,1 & 8,76 & 11,47 & 8,16 & 12,868 & 9,55 & 0,742 \\
\hline & Cap_Gir & 0,16 & 0,14 & 0,14 & 0.1 & 0.16 & 0,11 & 0,15 & 0,11 & 0,13 & 0,16 & 0,148 & 0,12 & 0,84 \\
\hline & ROA & 4,87 & 5,24 & 3,37 & 5,63 & 4,05 & 4,2 & 3,16 & 4,28 & 0,17 & 7,57 & 3,124 & 5,38 & 9,82 \\
\hline & ROE & 11,89 & 16,04 & 7,25 & 20,29 & 10,71 & 10,52 & 7,12 & 12,3 & $-40,5$ & 255,2 & $-0,714$ & 62,87 & 0,12 \\
\hline & MB & 31,99 & 17,53 & 29,61 & 17,61 & 31,61 & 16,72 & 30,2 & 14,1 & 27,15 & 14,9 & 30,116 & 16,17 & 0,538 \\
\hline & ML & 7,31 & 11,78 & 3,51 & 11,83 & 5,28 & 8,22 & 3,97 & 7,46 & $-4,01$ & 20,27 & 3,212 & 11,91 & 0,672 \\
\hline \multirow{9}{*}{ 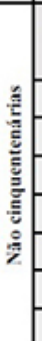 } & Vu & \multicolumn{2}{|c|}{2011} & \multicolumn{2}{|c|}{2012} & \multicolumn{2}{|c|}{2013} & \multicolumn{2}{|c|}{2014} & \multicolumn{2}{|c|}{2015} & \multicolumn{3}{|c|}{ Total } \\
\hline & Variaveis & Méd. & DP & Méd. & DP & Méd. & DP & Méd. & $\mathrm{DP}$ & Méd. & DP & Méd. & $\overline{D P}$ & Coef. var. \\
\hline & Caixa & 0,14 & 0,39 & 0,15 & 0,46 & 0,16 & 0.5 & 0,17 & 0.56 & 0,18 & 0,76 & 0,16 & 0,534 & 3,324 \\
\hline & Clientes & 0,21 & 0,4 & 0,21 & 0,39 & 0,19 & 0,34 & 0,19 & 0,39 & 0,18 & 0,36 & 0,196 & 0,376 & 1,902 \\
\hline & Cap_Gir & 0,65 & 1,8 & 0,63 & 1,72 & 0,61 & 1,99 & 0,69 & 3,04 & 0,43 & 1,71 & 0,602 & 2,052 & 3,426 \\
\hline & ROA & 5,37 & 7,66 & 4,71 & 7,26 & 3,02 & 15,94 & 2,27 & 13,6 & $-0,57$ & 16,9 & 2,96 & 12,272 & $-3,052$ \\
\hline & ROE & $-6,49$ & 209,4 & 9,12 & 33,47 & 7,39 & 32,19 & 9,58 & 42,4 & 94,1 & 800,2 & 22,74 & 223,5 & $-2,266$ \\
\hline & MB & 37,76 & 21,81 & 36,91 & 22,87 & 36,94 & 21,54 & 35,8 & 21,2 & 34,96 & 20,82 & 36,466 & 21,65 & 0,594 \\
\hline & ML & -32.88 & 348,7 & $-44,7$ & 467,1 & $-646,4$ & 5766.2 & 4,06 & 28,1 & -2.68 & 40.92 & $-144,52$ & 1330,2 & $-7,664$ \\
\hline
\end{tabular}

Fonte: elaborado pelos autores

Nota: Méd. é média, DP é XYZ e Coef. var. é Coeficiente de variação.

Conforme apresentado na Tabela 3, pela média do indicador caixa, observa-se que há uma evolução no período de 2011 a 2015, nas empresas cinquentenárias, onde inicia com o valor de 7,59 (2011) e apresenta ao final 9,78 (2015). Além disso, este indicador é a única variável da folga financeira que apresenta crescimento em todas as mudanças anuais. De forma similar, o indicador clientes é superior em empresas cinquentenárias para todos os anos, entretanto o capital de giro está mais presente em empresas não cinquentenárias.

As empresas não cinquentenárias também apresentam evolução de caixa, mas com uma variância muito inferior, além de apresentarem valores do indicador de caixa muito menores, com médias de 0,14 em 2011 e 0,18 em 2015. Em geral, os indicadores de caixa, clientes e capital de giro evidenciam que há diferenças na composição da folga financeira entre as empresas cinquentenárias e não cinquentenárias.

Como dois dos três indicadores da folga financeira (caixa e clientes) em empresas cinquentenárias apresentam médias superiores às não cinquentenárias, o resultado converge com o estudo Bradley et al. (2011) que afirma que as empresas mais jovens possuem mais dificuldades para obter recursos de capital. Já em relação ao capital de giro, que corresponde ao capital necessário para financiar as operações da empresa, este é utilizado mais em empresas não cinquentenárias que em cinquentenárias, o que converge com os estudos de George (2005) e Vanacker et al. (2013), pois possivelmente as cinquentenárias conseguem prever melhor os recursos provenientes às suas contas financeiras. 
O ROA possui valores semelhantes nas empresas cinquentenárias e nas não cinquentenárias, diferentemente dos valores de ROE, onde, em quase todos os anos, foi superior nas cinquentenárias, o que resulta em conformidade com George (2005), que argumenta que as empresas mais antigas possuem maior capacidade de agregar valor a ela mesma através dos seus próprios recursos.

Os níveis de $\mathrm{MB}$ são superiores para as não cinquentenárias, em todos os anos. Por outro lado, estas mostraram um decrescimento nos níveis de ML no período de 2011 a 2013, onde apresentaram -646,39 em 2013. Porém os resultados das empresas cinquentenárias em ML não constatam valores dessa magnitude, apesar de em determinadas mudanças de ano também evidenciar decrescimentos de pequena variância, o que expõe que as empresas não cinquentenárias lucraram muito menos do que as cinquentenárias, especificamente no período de 2011 a 2013.

Apesar de os valores das médias dos indicadores de folga financeira e desempenho econômico se manterem próximos, o desvio padrão nos períodos demonstra que há diferenças entre as empresas da pesquisa. Assim, a amostra apresenta-se heterogênea para as duas classificações de empresas, cinquentenárias e não cinquentenárias em todo o período, como também para todos os indicadores com coeficientes de variações superiores a 30\%, exceto no indicador ROE das empresas cinquentenárias.

$\mathrm{Na}$ Tabela 4, com a correlação de Pearson, é verificada a relação de caixa, cliente e capital de giro individualmente com cada indicador do desempenho econômico (ROA, ROE, ML e MB) para as empresas cinquentenárias e não cinquentenárias. 
TABELA 4.

Correlação de Pearson entre os índices de desempenho econômico e os índices da folga financeira nas empresas cinquentenárias e não cinquentenárias, no período de 2011 a 2015

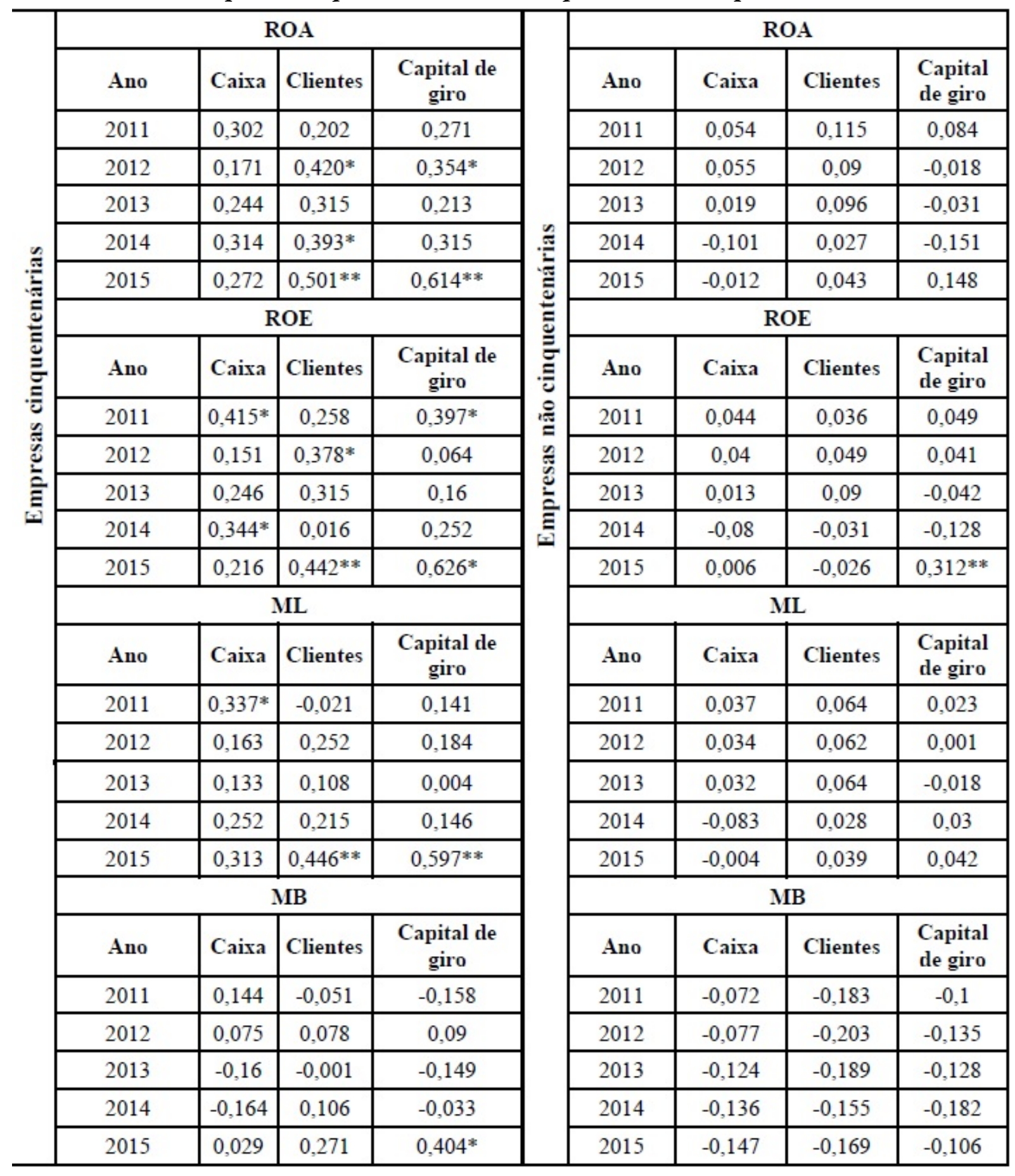

Fonte: elaborada pelo autores

* Sig. $90 \%$,

** Sig. 95\%,

*** Sig. $99 \%$

Os resultados obtidos para as empresas cinquentenárias mostram que há correlação positiva entre os indicadores clientes e capital de giro com o ROA; do ROE e a ML com o caixa, clientes e capital de giro para 
determinados anos, enquanto que a MB somente a tem com o capital de giro. A MB é a que menos apresentou correlação com os indicadores de folga financeira.

De maneira geral, as empresas não cinquentenárias praticamente não apresentaram correlações. Para estas só se verificou uma correlação em 2015 do capital de giro com o ROE, a diferença das empresas cinquentenárias. Possivelmente, empresas mais antigas possuem folga financeira mais relacionada com índices como ROA e ROE, contrário ao que acontece nas não cinquentenárias, onde esta correlação não é significativa. Estes resultados estão de acordo com os de George (2005), em que as empresas mais antigas possuem maior maturidade e melhor experiência para administrar recursos do que as mais jovens, e que, por consequência, a presença de folga financeira em empresas cinquentenárias tende a influenciar positivamente a rentabilidade, diferentemente das empresas não cinquentenárias.

Recomendam-se três critérios para a escolha das funções canônicas: (a) o nível de significância estatística ( $\mathrm{p}$ $<0,05)$, (b) a magnitude da correlação canônica (superior a 0,5) e (c) as medidas de redundância para os dois conjuntos. Neste estudo foram considerados os três critérios, onde a Tabela 5 mostra a correlação canônica, qui-quadrado, $\mathrm{R}^{2}$, teste de Shapiro-Wilk, a significância e as respectivas funções canônicas das empresas cinquentenárias e não cinquentenárias. A Tabela 6 , como as posteriores tabelas de análise de correlação canônica, foram obtidas a partir do software Statgraphics.

Ao considerar o primeiro critério, as funções 1 e 2 das empresas cinquentenárias foram estatisticamente significativas, porém ao observar a magnitude do segundo critério, verifica-se que somente a função 1 é superior a 0,5 . O coeficiente de determinação $\mathrm{R}^{2}$ mostra se o modelo proposto se ajusta adequadamente. Este coeficiente está entre 0 e 1 , onde quanto mais próximo de 1 , mais a curva estará ajustada aos dados; quanto mais próximo de 0, haverá menor relação entre a curva e os dados (Puente-Palacios, 1995).

Assim, a variância explicada é o $\mathrm{R}^{2}$ canônico, ou seja, é a correlação canônica elevada ao quadrado. Nas empresas cinquentenárias, $27,25 \%$ do conjunto dos indicadores de rentabilidade são influenciados pelo conjunto dos indicadores de folga financeira. Conforme a variância explicada, o grau de influência da folga financeira no desempenho econômico é baixo. 
TABELA 5.

Funções canônicas, significância e índices de redundância das variáveis para as empresas cinquentenárias e não cinquentenárias, no período de 2011 a 2015

\begin{tabular}{|c|c|c|c|c|c|}
\hline \multicolumn{6}{|c|}{ Empresas cinquentenárias } \\
\hline Função canônica & $\begin{array}{c}\text { Correlação } \\
\text { canônica }\end{array}$ & $\begin{array}{c}\text { Qui- } \\
\text { quadrado }\end{array}$ & $\mathbf{R}^{2}$ & $\begin{array}{l}\text { Lambda } \\
\text { de } \\
\text { Wilk's }\end{array}$ & Significância \\
\hline $\begin{array}{l}1,535 \mathrm{ROA}+0,454 \mathrm{ROE}-0,250 \mathrm{MB}-0,924 \mathrm{ML} \\
=0,087 \text { Caixa }+0,406 \text { Clientes }+0,694 \text { Capital } \\
\text { de giro }\end{array}$ & 0.522 & 71,920 & 0.272 & 0.655 & 0 \\
\hline $\begin{array}{l}(-1,218) \mathrm{ROA}+0,992 \mathrm{ROE}-0,124 \mathrm{MB}- \\
0,677 \mathrm{ML}=-0,255 \mathrm{Caixa}-1,068 \mathrm{Clientes}+ \\
0,996 \mathrm{Capital} \text { de giro }\end{array}$ & 0.289 & 17,826 & 0.083 & 0.9 & 0.007 \\
\hline $\begin{array}{l}(-0,844) \mathrm{ROA}-0,568 \mathrm{ROE}-0,480 \mathrm{MB}+ \\
1,816 \mathrm{ML}=1,036 \mathrm{Caixa}-0,249 \text { Clientes - } \\
0,231 \text { Capital de giro }\end{array}$ & 0.133 & 3,038 & 0.018 & 0.982 & 0.218 \\
\hline \multicolumn{6}{|c|}{ Empresas não cinquentenárias } \\
\hline Função canônica & $\begin{array}{c}\text { Correlação } \\
\text { canônica }\end{array}$ & $\begin{array}{c}\text { Qui- } \\
\text { quadrado }\end{array}$ & $\mathbf{R}^{2}$ & $\begin{array}{c}\text { Lambda } \\
\text { de } \\
\text { Wilk's }\end{array}$ & Significância \\
\hline $\begin{array}{l}(-0,949) \mathrm{ROA}+0,146 \mathrm{ROE}+0,828 \mathrm{MB}+ \\
0,361 \mathrm{ML}=1,737 \text { Caixa }-2,223 \text { Clientes }+ \\
0,103 \text { Capital de giro }\end{array}$ & 0.314 & 51,346 & 0.099 & 0.875 & 0 \\
\hline $\begin{array}{l}(-0,421) \mathrm{ROA}+0,679 \mathrm{ROE}-0,519 \mathrm{MB}+ \\
0,186 \mathrm{ML}=0,951 \text { Caixa }-0,721 \text { Clientes }+ \\
0,951 \text { Capital de giro }\end{array}$ & 0.161 & 11,400 & 0.026 & 0.971 & 0.076 \\
\hline $\begin{array}{l}0,617 \mathrm{ROA}+0,716 \mathrm{ROE}+0,342 \mathrm{MB}- \\
0,414 \mathrm{ML}=-1,126 \mathrm{Caixa}+0,214 \mathrm{Clientes}+ \\
0,480 \text { Capital de giro }\end{array}$ & 0.057 & 1,245 & 0.003 & 0.997 & 0.537 \\
\hline
\end{tabular}

Fonte: elaborado pelos autores

De acordo com os coeficientes (pesos canônicos) das empresas cinquentenárias, há uma maior utilização do ROA e o ROE, já que o sinal é positivo: o primeiro associa-se fortemente às variáveis explicativas e o segundo tem uma associação moderada com as variáveis independentes e uma menor utilização da ML. Ao analisar os pesos canônicos da conta clientes $(0,406)$ e capital de giro $(0,694)$, estes possuem uma relação positiva com o desempenho econômico, principalmente com o ROA $(1,535)$ e com o $\operatorname{ROE}(0,454)$, porém proporcionam uma menor utilização da ML (-0,924), no desempenho econômico.

Este resultado das empresas cinquentenárias tem concordância com Pimentel e Lima (2011) em partes, pois o ROA e o ROE foram utilizados como rentabilidade, porém comparado com liquidez seca, de qual a relação entre as variáveis foi positiva e que a carência em financiamento de capital de giro reflete tanto na redução dos índices de liquidez quanto na rentabilidade, o que corrobora os resultados de Enqvist, Graham e Nikkinen (2013) que indicam que a eficácia do capital de giro é essencial para a rentabilidade das empresas. O estudo de Wiseman e Bromiley (1996) também verificou uma relação positiva entre a liquidez e a rentabilidade. Entretanto Desai e Oza (2015) encontraram que a liquidez e a rentabilidade possuem uma relação negativa, e por isso é importante que a gestão faça um planejamento referente ao capital de giro.

Os resultados de Quayyum (2011) convergem parcialmente com os resultados deste estudo, visto que há confirmação pelos autores de uma relação negativa entre o ROA e o capital de giro e o ROA e os clientes, o que diverge dos resultados desta pesquisa. Além disso, o estudo de Quayyum encontrou uma relação negativa 
entre o capital de giro e a ML, aspecto que também é verificado neste estudo para as empresas cinquentenárias. Porém, diferentemente desta pesquisa, em Quayyum (2011), a relação negativa encontrada entre a ML e o capital de giro é baixa, enquanto que neste estudo o indicador capital de giro já possui uma influência moderada com relação à ML.

Pelo primeiro critério, a primeira função é significativa $(\mathrm{p}<0,05)$, nas empresas não cinquentenárias, porém a magnitude é inferior a 0,5 (0,314). A variância, explicada entre os dois conjuntos de variáveis dependentes e independentes, é de 9,86\%, onde, conforme Hair (2005), essa força de associação pode ser considerada como leve. Portanto, 9,86\% da variação da rentabilidade é influenciada pela folga financeira, ou seja, apesar de influência significativa, essa é considerada muito fraca.

Conforme a Tabela 5, o indicador de caixa $(1,737)$ tem uma relação positiva com o desempenho econômico na $\mathrm{MB}(0,828)$ e na $\mathrm{ML}(0,361)$, mas em contrapartida uma relação negativa com o desempenho econômico sobre o ROA (-0,949). Isto é concordante com a pesquisa de Eljelly (2004), na qual encontrou-se que a medida de liquidez que mais afeta a rentabilidade é o caixa ao ser comparado com o índice de liquidez corrente, o que verifica também que a relação é negativa e significativa.

Já, ao contrário do caixa, a menor previsão da conta clientes $(-2,223)$ resulta numa maior utilização da $\mathrm{MB}$ $(0,846)$ e ML $(0,361)$ no desempenho econômico, porém com menor utilização do ROA $(-0,949)$.

Ao considerar somente o ROA como indicador de rentabilidade, constatou-se que a relação entre a liquidez e a rentabilidade é negativa, isto diverge dos estudos de Wiseman e Bromiley (1996), onde observaram uma relação positiva. Contudo, esse resultado converge com a pesquisa de Desai e Oza (2015), os quais constataram que a liquidez corrente, representada pelo capital de giro, e que inclui o caixa nos ativos circulantes, possui uma relação negativa com a rentabilidade.

A Tabela 6 informa os índices de redundância das variáveis para as funções das empresas cinquentenárias e não cinquentenárias. Para encontrar os índices de redundância basta multiplicar o $\mathrm{R}^{2}$ pela variância compartilhada de cada um, o que gera um índice de redundância para os dependentes e outro para os independentes. $O$ índice de redundância das cinquentenárias monstra que a variância nas variáveis dependentes, explicada pela variável estatística canônica independente, e a variância nas variáveis independentes, explicada pela variável estatística canônica dependente, é muito baixo. 
TABELA 6.

Indices de redundância para as empresas cinquentenárias e não cinquentenárias, no periodo de 2011 a 2015

Índices de redundância para as empresas cinquentenárias e não cinquentenárias, no período de 2011 a 2015

\section{Empresas cinquentenárias}

\begin{tabular}{|l|l|l|l|}
\hline Variáveis & $\begin{array}{l}\text { Variância } \\
\text { compartilhada }\end{array}$ & $\mathbf{R}^{\mathbf{2}}$ & $\begin{array}{l}\text { Índice } \\
\text { redundância }\end{array}$ \\
\hline Dependentes & 0.163 & 0.272 & 0.044 \\
\hline Independentes & 0.31 & 0.272 & 0.084 \\
\hline Empresas não cinquentenárias & \multicolumn{3}{|l|}{ de } \\
\hline Variáveis & $\begin{array}{l}\text { Variância } \\
\text { compartilhada }\end{array}$ & $\mathbf{R}^{\mathbf{2}}$ & $\begin{array}{l}\text { Índice } \\
\text { redundância }\end{array}$ \\
\hline Dependentes & 0.253 & 0.099 & $\mathbf{0 . 0 2 5}$ \\
\hline Independentes & 2,842 & 0.099 & $\mathbf{0 . 2 8}$ \\
\hline
\end{tabular}

Fonte: elaborado pelos autores

Conforme a Tabela 6, o índice de redundância das não cinquentenárias monstra que a variância nas variáveis dependentes, explicada pela variável estatística canônica independente, é relevante, mas a variância nas variáveis independentes, explicada pela variável estatística canônica dependente, é consideravelmente inferior.

De modo geral, ao analisar os resultados do estudo, verificou-se uma relação mais forte entre folga financeira e desempenho econômico em empresas cinquentenárias do que em não cinquentenárias. Portanto, conforme Gompers e Lerner (2001), este resultado para cinquentenárias é, possivelmente, devido a estas empresas dependerem menos de fontes de recursos externos. De outro lado, a presença da folga financeira tende a ser uma estratégia para a elevação do desempenho econômico das cinquentenárias. Em contrapartida, as empresas não cinquentenárias, consideradas ainda não estáveis, estão mais voltadas ao desenvolvimento de capacidades e competências com o intuito de melhorar a sua posição de mercado, conforme às pesquisas de Damanpour e Wischnevsky (2006), Bradley et al., (2011) e Avadikyan et al., (2016), onde, possivelmente, a folga financeira não produz muitas vezes o mesmo impacto positivo sobre o desempenho econômico.

Assim, essas empresas são, geralmente, mais voltadas aos seus conhecimentos ou habilidades e dependem mais do estabelecimento de competências e capacidades para o alcance de uma posição no mercado, já que também possuem uma estrutura organizacional pequena, o que dificulta também seus relacionamentos com outras empresas (Damanpour \& Wischnevsky, 2006; Bradley et al., 2011). 


\section{Considerações finais}

O objetivo desta pesquisa consistiu em analisar a relação entre a folga financeira e o desempenho econômico em empresas de capital aberto e fazer um comparativo com empresas cinquentenárias e não cinquentenárias. Pode-se dizer que o objetivo foi alcançado, pois, com o respaldo da correlação canônica, concluiu-se que tanto em empresas cinquentenárias como em não cinquentenárias a folga financeira tem relação com o desempenho econômico. Em relação às evidências, verificou-se que as empresas cinquentenárias possuem grau de relação mais forte entre os dois conjuntos de indicadores, com 27,25\% de variância explicada, em contrapartida, as não cinquentenárias obtiveram $9,86 \%$ de variância explicada.

Em empresas não cinquentenárias, o capital de giro possui uma relação negativa com o desempenho econômico, no indicador ROA, pois quando os níveis de caixa e de clientes aumentam, o ROA diminui. Além disso, em empresas mais jovens, conforme seus ambientes mais instáveis, apresentam, de maneira geral, uma menor elevação da rentabilidade com a presença da folga financeira do que em empresas mais antigas, as quais já apresentam maturidade e certa estabilidade com recursos próprios.

Portanto, a folga financeira impacta praticamente o dobro, no desempenho econômico, nas empresas cinquentenárias. Nestas, pode-se afirmar que os indicadores de folga financeira, de clientes e do capital de giro têm relação positiva com o desempenho econômico com maior intensidade no ROA, porém não acontece o mesmo com o indicador de caixa. Ou seja, o desempenho econômico dessas empresas vai ser modificado por variações no capital de giro da empresa e nos recebíveis, mas não na conta caixa. Assim, pode-se concluir que os níveis de caixa das empresas cinquentenárias, por mostrarem mais segurança ao mercado para possíveis endividamentos, concentram-se mais na administração do capital de giro e também nas contas a receber de seus clientes para que possam elevar sua rentabilidade.

Esses resultados não podem ser generalizados, pois eles irão inferir apenas na amostra coletada. Podem haver discrepâncias, principalmente nos níveis de relação, se outras variáveis e outras empresas forem consideradas na análise. Além disso, o número reduzido de empresas, bem como a discrepância na literatura sobre indicadores de folga financeira e desempenho econômico podem ser evidenciados como restrições da presente pesquisa.

Como sugestão para os próximos estudos, a comparação dessas mesmas variáveis com empresas de países diferentes pode trazer resultados interessantes, bem como a expansão para outras variáveis, principalmente de folga financeira. Além disso, evidenciar a comparação entre empresas de capital aberto e empresas de capital fechado para poder assim evidenciar a situação real do cenário brasileiro, já que a quantidade de empresas de capital fechado no Brasil é substancialmente maior do que as de capital aberto. Também, sugere-se a relação de diferentes fatores, sejam eles monetários ou não monetários e que estejam evidenciados de acordo com o ciclo de vida das empresas, o que salienta as diferenças entre empresas com diferentes idades.

\section{Referências}

Antle, R., \& Eppen, G. D. (1985). Capital Rationing and Organizational Slack in Capital Budgeting. Management science, 31(2), 163-174. https://doi.org/10.1287/mnsc.31.2.163

Appuhami, B. R. (2008). The Impact of Firms' Capital Expenditure on Working Capital Management: An Empirical Study Across Industries in Thailand. International Management Review, 4(1), 8-21. http://hdl.handle.net/195 9.14/130798

Acemoglu, D., Aghion, P., Lelarge, C., Van Reenen, J., \& Zilibotti, F. (2007). Technology, Information, and the Decentralization of the Firm. The Quarterly Journal of Economics, 122(4), 1759-1799. DOI: 10.3386/w12206

Assaf Neto, A. (2010) Finanças corporativas e valor. 5. ed. São Paulo: Atlas. 
Avadikyan, A., Lhuillery, S., \& Negassi, S. (2016). Technological Innovation, Organizational Change, and ProductRelated Services.M@n@gement,19(4),277-304.

Bourgeois, L. J., III (1981). On the Measurement of Organizational Slack. Academy of Management review, 6(1), 29-39. DOI: $10.2307 / 257138$

Bradley, S. W., Shepherd, D. A., \& Wiklund, J. (2011). The Importance of Slack for New Organizations Facing 'Tough' Environments. Journal of Management Studies, 48(5), 1071-1097. https://doi.org/10.1111/ j.1467-6486.2009.00906.x

Braga, R., Nossa, V., \& Marques, J. A. V. D. C. (2004). Uma proposta para a análise integrada da liquidez e rentabilidade das empresas. Revista Contabilidade \& Finanças, 15(SPE), 51-64. http://dx.doi.org/10.1590/ S1519-70772004000400004

Camargos, M. A., \& Barbosa, F. V. (2005). Análise do desempenho econômico-financeiro e da criação de sinergias em processos de fusões e aquisições do mercado brasileiro ocorridos entre 1995 e 1999. REGE Revista de Gestão, 12(2), 99-115. http://dx.doi.org/10.5700/issn.2177-8736.rege.2005.36520

Campos, A. L. S., \& Nakamura, W. T. (2015). Rebalanceamento da Estrutura de Capital: Endividamento Setorial e Folga Financeira. Revista de Administração Contemporânea, 19(SPE), 20-37. http:// dx.doi.org/10.1590/1982-7849rac20151789

Cheng, J. L., \& Kesner, I. F. (1997). Organizational Slack and Response to Environmental Shifts: The Impact of Resource Allocation Patterns. Journal of Management, 23(1), 1-18. https://doi.org/10.1016/ S0149-2063(97)90003-9

Dai, W., \& Kittilaksanawong, W. (2014). How Are Different Slack Resources Translated into Firm Growth? Evidence from China. International Business Research, 7(2), 1-12. http://dx.doi.org/10.5539/ibr.v7n2p1

Dalmácio, F. Z. (2009). Mecanismos de governança e acurácia das previsôes dos analistas do mercado brasileiro: uma análise sob a perspectiva da teoria da sinalização. (Tese de doutorado). Universidade de São Paulo, São Paulo, SP, Brasil. DOI: 10.11606/T.12.2009.tde-17122009-171118.

Damanpour, F. (1987). The Adoption of Technological, Administrative, and Ancillary Innovations: Impact of Organizational Factors. Journal of Management, 13(4), 675-688. https:// doi.org/10.1177/014920638701300408

Damanpour, F., \& Wischnevsky, J. D. (2006). Research on Innovation in Organizations: Distinguishing InnovationGenerating from Innovation-Adopting Organizations. Journal of Engineering and Technology Management, 23(4), 269-291. https://doi.org/10.1016/j.jengtecman.2006.08.002

Daniel, F., Lohrke, F. T., Fornaciari, C. J., \& Turner, R. A., Jr. (2004). Slack Resources and Firm Performance: a MetaAnalysis. Journal of Business Research, 57(6), 565-574. https://doi.org/10.1016/S0148-2963(02)00439-3

Desai, H. \& Oza, V. (2015) A Comparative Study of Working Capital Management of Dabur India and Marico. Global Journal of Multidisciplinary Studies, 4(7), 178-183.

Eljelly, A. M. A. (2004). Liquidity-Profitability Tradeoff: An Empirical Investigation in an Emerging Market. International Journal of Commerce and Management, 14(2), 48-61. https:// doi.org/10.1108/10569210480000179

Enqvist, J., Graham, M., \& Nikkinen, J. (2014). The Impact of Working Capital Management on Firm Profitability in Different Business Cycles: Evidence from Finland. Research in International Business and Finance, 32(C), 36-49. DOI: $10.1016 /$ j.ribaf.2014.03.005

Epley, D. (2001). US Real Estate Agent Income and Commercial/Investment Activities. Journal of Real Estate Research, 21(3), 221-244

Ehrhardt, M. C; Brigham, E. F. (2012). Administração financeira: teoria e prática. 2. ed. São Paulo: Cengage Learning.

Fávero, L. P. L. (2005) O mercado imobiliário residencial da região metropolitana de São Paulo: uma aplicação de modelos de comercialização hedônica de regressão e correlação canônica. (Tese de Doutorado) Universidade de São Paulo FEA-USP, São Paulo, SP, Brasil. DOI: 10.11606/T.12.2005.tde-05122005-151150

Ferreira, J. A. S. (2005). Finanças corporativas: conceitos e aplicaçôes. São Paulo: Pearson Prentice Hall. 
George, G. (2005). Slack Resources and the Performance of Privately Held Firms. Academy of Management Journal, 48(4), 661-676. https://doi.org/10.5465/amj.2005.17843944.

Gitman, L. J. (2010). Princípios de administração financeira. 12. ed. São Paulo: Pearson.

Gompers, P., \& Lerner, J. (2001). The Venture Capital Revolution. Journal of Economic Perspectives, 15(2), 145-168. DOI: $10.1257 /$ jep.15.2.145

Greenley, G. E., \& Oktemgil, M. (1998). A Comparison of Slack Resources in High and Low Performing British Companies. Journal of management Studies, 35(3), 377-398. https://doi.org/10.1111/1467-6486.00098

Hair, J. F., Anderson, R. E., Tatham, R. L. \& Black, W. C. (2005). Análise multivariada de dados. 5 ed. Porto Alegre: Bookman.

Hitt, M. A., Xu, K., \& Carnes, C. M. (2016). Resource Based Theory in Operations Management Research.Journal of Operations Management, 41, 77-94. https://doi.org/10.1016/j.jom.2015.11.002

Iyer, D. N., \& Miller, K. D. (2008). Performance Feedback, Slack, and the Timing of Acquisitions. Academy of Management Journal, 51(4), 808-822. https://doi.org/10.5465/amr.2008.33666024

John, K., Li, Y., \& Pang, J. (2016). Does Corporate Governance Matter More for High Financial Slack Firms?. Management Science, 63(6), 1872-1891. https://doi.org/10.1287/mnsc.2015.2392

Ju, M., \& Zhao, H. (2009). Behind Organizational Slack and Firm Performance in China: The Moderating Roles of Ownership and Competitive Intensity. Asia Pacific Journal of Management, 26(4), 701-717. https:// doi.org/10.1007/s10490-009-9148-1

Kim, H., Kim, H., \& Lee, P. M. (2008). Ownership Structure and the Relationship Between Financial Slack and R\&D Investments: Evidence from Korean Firms. Organization Science, 19(3), 404-418. https://doi.org/10.1287/ orsc. 1080.0360 .

Laffranchini, G., \& Braun, M. (2014). Slack in Family Firms: Evidence from Italy (2006-2010). Journal of Family Business Management, 4(2), 171-193. https://doi.org/10.1108/JFBM-04-2013-0011

Lin, X., \& Zhang, Y. (2009). Bank Ownership Reform and Bank Performance in China.Journal of Banking \& Finance, 33(1), 20 29. https://EconPapers.repec.org/RePEc:eee:jbfina:v:33:y:2009:i:1:p:20-29

Matarazzo, D. C. (2010) Análise financeira de balanços: abordagem gerencial.7 ed. São Paulo: Atlas.

Mathur, I., \& Banchuenvijit, W. (2007). The Effects of Privatization on the Performance of Newly Privatized Firms in Emerging Markets. Emerging Markets Review, 8(2), 134-146. https://doi.org/10.1016/j.ememar.2006.12.002.

Mingoti, S. A. (2005) Análise de dados através de métodos de estatística multivariada: uma abordagem aplicada. Belo Horizonte: Ed. UFMG

Myers, S. C., \& Majluf, N. S. (1984). Corporate Financing and Investment Decisions when Firms have Information that Investors do not Have. Journal of Financial Economics, 13(2), 187-221. https:// doi.org/10.1016/0304-405X(84)90023-0.

Mylonidis, N., \& Kelnikola, I. (2005). Merging Activity in the Greek Banking System: A Financial Accounting Perspective. South Eastern Europe Journal of Economics, 3(1), 121-144. https://EconPapers.repec.org/RePEc:s eb:journl:v:3:y:2005:i:1:

Namiki, N. (2012) The Impact of Slack Reduction on Performance Turnaround during the Great Recession: The Case of Japanese Electronics Companies. International Proceedings of Economics Development and Research, 50(6), 24-28.

Nohria, N., \& Gulati, R. (1996). Is Slack Good or Bad for Innovation? The Academy of Management Journal, 39(5), 1245-1264. DOI: $10.2307 / 256998$.

Pimentel, R. C., \& Lima, I. S. (2011). Relação trimestral de longo prazo entre os indicadores de liquidez e de rentabilidade: evidência de empresas do setor têxtil. Revista de Administração, 46(3), 275-289. https:// doi.org/10.5700/rausp1012

Puente-Palacios, K. E. (1995). Influências das características pessoais e ambientais na avaliação do clima social do trabalho. Revista de Administração, 30(3), 73-79. 
Quayyum, S. T. (2011). Relationship Between Working Capital Management and Profitability in Context of Manufacturing Industries in Bangladesh. International Journal of Business and Management, 7(1), 58-69. https:// doi.org/10.5539/ijbm.v7n1p58.

Ross, S. A., Westerfield, R. W. \& Jaffe, J. F. D. (2015). Administração financeira. 10 ed. São Paulo: McGraw-Hill/ Bookman.

Satta, G., Parola, F., Penco, L., \& Esposito de Falco, S. (2016). Insights to Technological Alliances and Financial Resources as Antecedents of High-Tech Firms' Innovative Performance. R\&D Management, 46(S1), 127-144. DOI: $10.1111 / \mathrm{radm} .12117$.

Scarpel, R. A. \& Milioni, A. Z. (2001) Aplicação de modelagem econométrica à análise financeira de empresas. Revista de Administração da Universidade de São Paulo (RAUSP), 36(2), 80-88.

Shaikh, I. A., O'Brien, J. P., \& Peters, L. (2018). Inside Directors and the Underinvestment of Financial Slack Towards R\&D-Intensity in High-Technology Firms. Journal of Business Research, 82(C), 192-201. DOI: 10.1016/ j.jbusres.2017.09.014.

Sharfman, M. P., Wolf, G., Chase, R. B., \& Tansik, D. A. (1988). Antecedents of Organizational Slack. Academy of Management Review, 13(4), 601-614. https://doi.org/10.5465/amr.1988.4307484

Silveira, A. D. M. D. (2002). Governança corporativa, desempenho e valor da empresa no Brasil. (Dissertação de Mestrado) Universidade de São Paulo - USP. São Paulo, SP, Brasil.DOI: 10.11606/ D.12.2002.tde-04122002-102056.

Singh, J. V. (1986). Performance, Slack, and Risk Taking in Organizational Decision Making. Academy of Management Journal, 29(3), 562-585. DOI: 10.2307/256224.

Su, Z., Xie, E., \& Li, Y. (2009). Organizational Slack and Firm Performance During Institutional Transitions. Asia Pacific Journal of Management, 26(1), 75-91. https://doi.org/10.1007/s10490-008-9101-8

Tan, J., \& Peng, M. W. (2003). Organizational Slack and Firm Performance During Economic Transitions: Two Studies from an Emerging Economy. Strategic Management Journal, 24(13), 1249-1263. https://doi.org/10.1002/ smj.351

Vanacker, T., Collewaert, V., \& Paeleman, I. (2013). The Relationship Between Slack Resources and the Performance of Entrepreneurial Firms: The role of Venture Capital and Angel Investors. Journal of Management Studies, 50(6), 1070-1096. https://doi.org/10.1111/joms.12026

Voss, G. B., Sirdeshmukh, D., \& Voss, Z. G. (2008). The Effects of Slack Resources and Environmental Threat on Product Exploration and Exploitation. Academy of Management Journal, 51(1), 147-164. DOI: $10.2307 / 20159499$

Weston, J. F.; Brigham, E. F. (2000) Fundamentos da administração financeira.10. ed. São Paulo: Pearson Education do Brasil.

Wiseman, R. M., \& Bromiley, P. (1996). Toward a Model of Risk in Declining Organizations: An Empirical Examination of Risk, Performance and Decline. Organization Science, 7(5), 524-543. https://doi.org/10.1287/ orsc.7.5.524.

Woodman, R. W., Sawyer, J. E., \& Griffin, R. W. (1993). Toward a Theory of Organizational Creativity. Academy of Management Review, 18(2), 293-321. DOI: 10.2307/258761.

Yu, Q., Miche, Y., Séverin, E., \& Lendasse, A. (2014). Bankruptcy Prediction Using Extreme Learning Machine and Financial Expertise. Neurocomputing, 128, 296-302. DOI: 10.1016/j.neucom.2013.01.063

\section{Licencia Creative Commons CC BY 4.0}

Para citar este artigo: Da Silva, T. P, Rohenkohl, L. B. \& Bizatto, L. S. (2018). Relação entre folga financeira e desempenho econômico em empresas cinquentenárias e não cinquentenárias. Cuadernos de Contabilidad, 19(47), 130-148. https://doi.org/10.11144/Javeriana.cc19-47.ffde 